\title{
STAT3, a Key Parameter of Cytokine-Driven Tissue Protection during Sterile Inflammation - the Case of Experimental Acetaminophen (Paracetamol)-Induced Liver Damage
}

Heiko Müh/*

Pharmazentrum Frankfurt/ZAFES, University Hospital Goethe-University Frankfurt am Main, Frankfurt am Main, Germany

OPEN ACCESS

Edited by:

Mariagrazia Uguccioni, Institute for Research in Biomedicine, Switzerland

Reviewed by: Jean-Christophe Renauld, Ludwig Institute for Cancer Research, Belgium Jo A. Van Ginderachter, VIB-Vrije Universiteit Brussel, Belgium

${ }^{*}$ Correspondence: Heiko Mühl h.muehl@em.uni-frankfurt.de

Specialty section: This article was submitted to Inflammation,

a section of the journal

Frontiers in Immunology

Received: 20 February 2016 Accepted: 15 April 2016

Published: 02 May 2016

Citation:

Mühl H (2016) STAT3, a Key Parameter of Cytokine-Driven Tissue

Protection during Sterile Inflammation - the Case of

Experimental Acetaminophen

(Paracetamol)-Induced Liver Damage.

Front. Immunol. 7:163. doi: 10.3389/fimmu.2016.00163
Acetaminophen (APAP, $N$-acetyl- $p$-aminophenol, or paracetamol) overdosing is a prevalent cause of acute liver injury. While clinical disease is initiated by overt parenchymal hepatocyte necrosis in response to the analgetic, course of intoxication is substantially influenced by associated activation of innate immunity. This process is supposed to be set in motion by release of danger-associated molecular patterns (DAMPs) from dying hepatocytes and is accompanied by an inflammatory cytokine response. Murine models of APAP-induced liver injury emphasize the complex role that DAMPs and cytokines play in promoting either hepatic pathogenesis or resolution and recovery from intoxication. Whereas the function of key inflammatory cytokines is controversially discussed, a subclass of specific cytokines capable of efficiently activating the hepatocyte signal transducer and activator of transcription (STAT)-3 pathway stands out as being consistently protective in murine models of APAP intoxication. Those include foremost interleukin (IL)-6, IL-11, IL-13, and IL-22. Above all, activation of STAT3 under the influence of these cytokines has the capability to drive hepatocyte compensatory proliferation, a key principle of the regenerating liver. Herein, the role of these specific cytokines during experimental APAP-induced liver injury is highlighted and discussed in a broader perspective. In hard-to-treat or at-risk patients, standard therapy may fail and APAP intoxication can proceed toward a fatal condition. Focused administration of recombinant STAT3-activating cytokines may evolve as novel therapeutic approach under those ill-fated conditions.

Keywords: acetaminophen, acute liver injury, hepatocytes, STAT3, IL-6, IL-11, IL-13, IL-22

\section{INTRODUCTION}

Acute liver injury (ALI) is a major burden of health care systems worldwide. Viral infections and side effects of pharmacotherapy stand out among pathological challenges provoking ALI. Specifically, overdosing of the weak-to-moderate analgesic acetaminophen (APAP; $N$-acetyl-p-aminophenol; or paracetamol) is regarded as one major cause of ALI in the developed countries. Notably, over-the-counter availability, underrated toxicity, and a narrow therapeutic margin further APAP 
misuse/intoxication which, if not timely treated with its antidote $\mathrm{N}$-acetylcysteine, can proceed toward a fulminant condition requiring transplantation for patient survival (1-3).

Specifically, APAP is hold responsible for up to 80,000 emergency visits, 2500 hospitalizations and 500 fatal intoxications in the United States annually $(2,4)$. A recent study analyzing between 2005 and 2007 patients from selected European countries documented 114 drug overdose-related cases of ALI demanding transplantation (of 600 totals). Ninety-seven percent (111 cases) of those concerned APAP (5). In Germany, 850 hospitalizations due to APAP intake were recorded 2012 for patients with statutory health insurance. However, only four fatalities were documented (6). Altogether, epidemiological studies indicate noticeable variations in the incidence of severe APAP-induced ALI in different populations within Europe (5) and the developed countries altogether.

On a cellular level, liver injury by APAP is regarded a two-hit process involving initial direct induction of hepatocyte cell death and, subsequent to that, activation of innate immunity that triggers an inflammatory response having the complex potential to either aggravate disease or to actually support tissue repair and hepatic regeneration (7-12).

Hepatocyte cell death, being at the root of APAP toxicity, is dependent on drug metabolizing cytochrome P450 enzymes (Cyp), particularly Cyp2e1 and Cyp1a2 $(8,13)$. These enzymes generate from APAP poisonous $N$-acetyl- $p$-benzoquinone imine (NAPQI), a highly reactive metabolite capable of coupling to protein sulfhydryl groups thereby disturbing hepatocyte cell physiology. Specifically, NAPQI mediates mitochondrial oxidative stress, drop in ATP generation, c-jun N-terminal kinase (JNK) activation, and eventually cell death $(8,14)$. Although apoptosis and necrosis as well as necrosis-related necroptosis have all been detected during experimental APAP-induced ALI, the latter two types of cell demise prevail in the context of pathological intoxication. Notably, as opposed to immune-deactivating apoptosis, necrosis and necroptosis connect to activation of innate immunity and inflammation $(7,8,14,15)$ whereby the leukocytic cell compartment becomes involved into course and outcome of APAP-induced ALI.

\section{THE COMPLEX ROLE OF INNATE IMMUNITY AND INFLAMMATORY CYTOKINES IN EXPERIMENTAL MURINE APAP-INDUCED LIVER INJURY}

Key to sterile necro-inflammation, as detected in APAP-induced ALI, is release of danger-associated molecular patterns (DAMPs) from cells undergoing necrosis. Once increasingly present in the extracellular compartment or later on taken up by leukocytes, those are detected by sensors of innate immunity, e.g., toll-like receptors (TLR), setting in motion inflammatory processes that can drive pathology but also setting the stage for parenchymal tissue repair and regeneration $(9-12,16,17)$.

DAMPs reported to mediate pathological immunoactivation during APAP-induced ALI include high-mobility group box 1 protein (HMGB1) (18-20) and histones (21). Both couple to
TLR4 on hepatic monocytes/macrophages, including resident Kupffer cells. Besides that, HMGB1 was found to activate the receptor for advanced glycation end product (RAGE) on neutrophils, whereas histones may mediate pathological effects also via TLR2. Nucleic acids released from necrotic hepatocytes likewise display a strong potential to aggravate APAP intoxication by action on TLR sensors. Specifically, DNA targeting TLR9 $(22,23)$ and RNA targeting leukocytic or hepatocyte TLR3 (24) contribute to hepatic injury. A pivotal role for TLR9 was confirmed by pharmacological application of a small-molecule TLR9 antagonist to mice undergoing APAP intoxication (25). Among DAMPs sensed independently from the TLR system, ATP and uric acid stand out. Both can aggravate APAP-induced ALI (26-28) supposedly by action on the inflammasome, a multiprotein complex consisting of interleukin (IL)-1 $/ / \mathrm{IL}-18$ activating caspase-1. In this scenario, ATP binds to purinergic $\mathrm{P}_{2} \mathrm{X}_{7}$ receptors on monocytes/macrophages (including Kupffer cells) at the hepatic microenvironment connecting to cellular $\mathrm{K}^{+}$-efflux and subsequent inflammasome activation. After being released by dying cells or derived from degradation of nucleic acids, uric acid, on the other hand, is taken up in the form of crystals that directly activate inflammasomes and, thus, IL-1 $\beta$ / IL-18-dependent inflammation $(29,30)$.

Although, at first sight, it appears obvious that innate immunity and sterile inflammation amplify pathogenesis of APAP-induced ALI, this topic in fact is controversially discussed. For example, while several studies indicate a pathological role of TLR4 $(21,31,32)$, a recent report did not endorse a disease-promoting but rather a protective function of myeloid TLR4 signaling in APAP-related liver damage. Interestingly, deleterious action of RAGE and TLR9 was confirmed in this same study (33). Another recent report disputed a pathogenic role for $\mathrm{P}_{2} \mathrm{X}_{7}$ receptors in APAP intoxication (34). While some parameters, such as mice characteristics, including their microbiome (35), or APAP dosage cannot be fully ruled out as sources of discrepancies, those divergent observations may actually reflect janus-faced functions of innate immunity and sterile inflammation in APAP-induced ALI - aggravating tissue damage, likely at an early phase of disease, but simultaneously displaying the strong potential to initiate and perpetuate hepatic repair and regeneration (36). The unique ability of the liver to, upon injury, most efficiently initiate processes aiming at preservation of organ function is driven by initial hepatocyte hypertrophy (increase in size) and an adjacent proliferative phase enabling compensatory hyperplasia $(37,38)$. Notably, if hepatic damage stays below a pathological threshold, the regenerative capacity of the liver can fully restore organ function in response to $\operatorname{APAP}(39,40)$.

The remarkable fact of quite divergent observations concerning the role of sterile inflammation in APAP-induced ALI particularly applies to the function of nuclear factor- $\mathrm{KB}$ (NF-kB)-activating inflammatory cytokines that are induced adjacent-distal to innate sensing. This specifically holds true for prototypic IL-1 and tumor necrosis factor (TNF)- $\alpha$ (41), both produced during APAP-induced ALI (22, 24, 42-46). Whereas aggravation of disease by pretreatment of mice with recombinant TNF $\alpha$ is undisputed (47), modulation of endogenous TNF $\alpha$ biological activity, as achieved by administering neutralizing 
antibodies or by investigating TNF receptor-1-deficient mice, resulted in quite heterogeneous outcome. Reports, on the one hand, demonstrate amelioration of APAP-induced toxicity by application of anti-TNF $\alpha$ antibodies $(48,49)$ or by using TNF receptor-1-deficient mice (49). By contrast, other reports observed either no effect of TNF $\alpha$-neutralization $(50,51)$ or even aggravation of disease as detected using TNF receptor1 -deficient mice $(52,53)$. Those latter two studies actually indicate a tissue-protective function of endogenous $\mathrm{TNF} \alpha$ in APAP-induced ALI that coincides with enhanced hepatocyte proliferation and activation of the key pro-regenerative transcription factor signal transducer and activator of transcription (STAT)-3 (54). To assess the role of IL-1 in APAP-toxicity is likewise puzzling. Either pathogenic functions $(22,55)$, no major role (42), or protection (56) by IL-1 has been put on record. The view that inflammatory cytokines, such as IL- 1 and TNF $\alpha$, have the potential to actually promote liver regeneration was recently

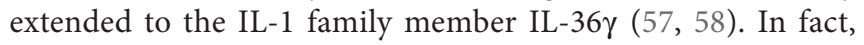
administration of IL-36 receptor antagonist and thus blockage of IL-36 biological activity during APAP-induced ALI impairs recovery in the late phase of intoxication (58). Interestingly, IL-36 mediating tissue protection likewise applies to intestinal healing $(59,60)$.

Altogether, current data support the concept that sterile inflammation and accompanied NF- $\kappa \mathrm{B}$-activating cytokines may promote hepatic repair and regeneration particularly in the later phase of APAP toxicity thereby affecting disease outcome (12). It is tempting to speculate that secondary induction of STAT3-activating cytokines, alike IL-6 (61), by NF- $\kappa B$-activating cytokines essentially contributes to the vital process of restoring liver homeostasis in response to APAP.

\section{STAT3 IN HEPATIC REPAIR AND REGENERATION}

STAT-3 is a member of the STAT family of transcription factors, which exerts decisive and context-dependent functions in inflammation, tissue survival, and carcinogenesis. Those characteristically include promotion of anti-apoptosis, proliferation, and stress resistance. Efficient activation of STAT3 is achieved under the influence of specific cytokines displaying janus-kinase signaling but also by selected growth factors, among others epidermal and platelet-derived growth factor. Phosporylation at Tyr705 is regarded a hallmark of STAT3 activation that couples to protein dimerization, nuclear translocation, and regulation of gene expression (62-65). In addition, phosphorylation at Ser727 $(63,65)$ and/or protein acetylation (66) amplify, whereas S-nitrosylation at Cys259 (67) and/or protein sumoylation (68) curb STAT3 activity. As already alluded to, enforcing hepatocyte anti-apoptosis and proliferation is key to liver protection by STAT3. Those functions are achieved by upregulation of gene products pivotally involved in cell fate decisions, among others, B-cell lymphoma-extra large $(b c l x L)$, myeloid cell leukemia-1 (mcl1), or survivin mediating anti-apoptosis as well as c-myc ( $m y c)$, cyclin B1/D1 (ccnb1/ccnd1), or cyclin-dependent kinase-2 $(c d c 2)$ mediating proliferation $(62,63)$.
The albumin-promoter was used to generate hepatocytespecific conditional STAT3 knockout mice in order to address the role of STAT3 in this cell type. Experiments revealed that hepatocyte STAT3 is, to a substantial part, accountable for hepatocyte proliferation and liver regeneration after murine partial hepatectomy. Notably, hepatocyte c-myc expression is aberrant and its inducibility retarded in aforementioned conditional STAT3deficient mice undergoing this procedure (69). In a study using a similar approach, hepatocyte STAT3 was functionless regarding parameters of liver injury evaluated in early APAP-induced ALI. However, analysis in that study was performed only $6 \mathrm{~h}$ after APAP administration and, thus, in the initial phase of intoxication (70) - leaving open the question of STAT3 functions during the later repair/regeneration phase. Notably, increased STAT3 activation in murine liver is still detectable $24 \mathrm{~h}$ after APAP application (71); the same holds true for expression of STAT3activating IL-6 $(72,73)$.

\section{TISSUE PROTECTION BY STAT3-ACTIVATING CYTOKINES AS DETECTED IN APAP-INDUCED ALI: IL-6, IL-11, IL-13, AND IL-22 - AND IL-10}

Whereas the role of NF- $\kappa \mathrm{B}$-activating cytokines in APAPinduced ALI appears complex and bewildering, STAT3-activating cytokines capable of directly targeting hepatocytes must be regarded as major drivers of liver regeneration. Those include IL-6, IL-11, IL-13, and IL-22.

Interleukin-6 is the flagship of a family of cytokines operating through transmembrane gp130 as signal transducing unit thereby coupling to activation of STAT transcription factors, in case of IL-6 foremost STAT3 (61). This also applies to its cytokine sibling IL-11 (74). Both, IL-6 and IL-11, are upregulated during initial hepatocyte injury and stay elevated, along with activated STAT3 (71), in the repair/regeneration phase at $24 \mathrm{~h}$ after APAP administration to mice $(72,73)$. In fact, protection by endogenous IL-6 was observed early on. Particularly in time-wise advanced disease $24 \mathrm{~h}$ (73) or $48 \mathrm{~h}$ (75) after APAP administration, IL-6-deficient mice endure aggravated toxicity associated with low production of hepatocyte-associated proliferating cell nuclear antigen (PCNA) and weakened liver macrophage inflammatory protein-2 (MIP-2) expression (75). Both, PCNA and MIP-2 (76), are key parameters of hepatocyte proliferation under the influence of APAP. Those observations suggest impaired recovery upon lack of IL-6. As expected, treatment of IL- 6 deficient mice with recombinant IL-6 attenuated retardation of repair and regeneration (75). It is noteworthy that hepatocytes are among the few non-leukocytic cell types expressing functional IL-6 receptors and, thus, allow classical IL-6 signaling. Despite this fact, recent data indicate that trans-signaling by soluble IL-6R/IL- 6 complexes $(61,77)$ is essential for the function of this cytokine during APAP-induced ALI (78). In fact, specific blockage of IL-6 trans-signaling by sgp $130 \mathrm{Fc}$ (77) substantially exacerbated disease (78); whereas pretreatment of mice with hyper-IL-6 (77), a recombinant agent specifically activating trans-signaling, ameliorated APAP toxicity - albeit to a more moderate degree (78). 
Interleukin-11 is a further STAT3-activating member of the IL-6 family directly targeting hepatocytes $(74,79)$ and, in stark contrast to IL-6, is efficiently expressed by inflamed/stressed hepatocytes under the influence of APAP (71). Autocrine or paracrine action may, thus, ensure high local IL-11 bioactivity that likely feeds back on the course of APAP-induced ALI. Notably, early data already revealed amelioration of murine APAP-toxicity by recombinant human IL-11 (80). This observation has been corroborated recently. A super-active modification of human IL-11 indeed enhanced protective hepatocyte compensatory proliferation in diseased mice. In female IL-11 receptor-deficient mice (IL11R $\mathrm{R}^{--}$) aggravated toxicity and diminished hepatocyte proliferation indicate a significant role for endogenous IL-11 during APAP-induced ALI. Interestingly, this observation does not apply to male $I L 11 R a^{-1-}$ mice that actually display compensatory augmentation of supposedly protective IL-6 (71). It should be emphasized that female mice, compared to males, generally display reduced sensitivity toward APAP that is connected to an enhanced capability in females to restore hepatocyte mitochondrial glutathione levels (81).

Interleukin-13 is renowned as key Th2 cytokine that, however, is produced by various cell types of foremost leukocytic origin. By binding to its heterodimeric IL-4R $\alpha / \mathrm{IL}-13 \mathrm{R} \alpha 1$ receptor complex, IL-13 activates STAT3 (along with STAT6) in even more diverse cell types (82), including murine hepatocytes (83). Elevated systemic levels of IL-13 are well-detectable at 4, 12, and $24 \mathrm{~h}$ after APAP administration to mice $(51,84)$. Notably, exacerbated disease connecting to IL-13 blockage by neutralizing antibodies or lack of bioactivity in knockout mice firmly indicates protection by this cytokine during APAP intoxication (51). Activation of hepatocyte STAT3 by IL-13 (83) suggests direct protective action during APAP-induced ALI. However, upregulation of the supposedly detrimental IL-12/IFN $\gamma$-axis (72) during intoxication in IL-13-deficient mice (51) additionally implicates macrophageaddressing immunomodulatory functions of IL-13 (85). Whether administration of surplus recombinant IL-13 can ameliorate APAP-induced ALI has, to the best of our knowledge, not been investigated.

Interleukin-22 is mainly a lymphocyte-derived member of the IL-10 cytokine family that gained significant attention due to tissue-protective properties largely mediated by STAT3 activation specifically in epithelial (-like) cells, including hepatocytes. Accordingly, IL-22 mediates favorable effects in various preclinical disease models affecting biological barriers at the lung, intestine, and liver. Notably, IL-22 generally does not activate leukocytes (86-88). A single dosage of recombinant IL-22 is actually sufficient to ameliorate APAP toxicity in mice $(43,70)$. Protection by IL-22 is dependent on STAT3 (70), does not involve modulation of APAP-metabolizing cytochrome P450 enzymes but is associated with increased compensatory hepatocyte proliferation (43). The role of endogenous IL-22 during APAP-induced ALI has, to the best of our knowledge, not been investigated. Recently, a functionally relevant aspect of IL-22 biology attracted attention. A potent synergism between the IFN signaling system and IL-22 concerning activation of STAT1 was identified in human colon carcinoma cells, HepG2 hepatoma cells, and primary keratinocytes on a biochemical level
(89). In contrast to STAT3, STAT1 (e.g., activated by IFN $\gamma$ ) promotes cell death, inhibits proliferation, is generally considered pro-inflammatory (90), and pathogenic in APAP-induced ALI (72). This regulatory path has recently been extended to murine in vivo pathology during viral infection (91) or graft-versus-host disease (92) and may affect the function of IL-22 not only under conditions of overt IFN production but likewise in the context of typ I IFN immunotherapy (90).

Interleukin-10 is a mainly leukocyte-derived protein that drops out of the list of aforementioned STAT3-activating cytokines because it is supposed to act foremost on leukocytic cells. IL-10 serves as principal deactivator of $\mathrm{T}$ cells and in particular of mononuclear phagocytes thereby modulating in STAT3-dependent manner inflammatory processes $(93,94)$ and holding in check potentially poisonous mediators, among others inducible nitric oxide (NO) synthase (95) -derived NO (84). During APAP intoxication systemic levels and hepatic expression of IL-10 increase. Notably, IL-10 deficient mice display enhanced sensitivity to APAP-induced ALI, which is unrelated to APAP metabolism but detectable on the level of serum ALT, morphologically, and by analysis of mortality rates (84). Since STAT3 can principally drive IL-10 expression $(93,96,97)$, this regulatory path may possibly contribute to tissue protection by STAT3-activating cytokines, such as IL-6. However, the therapeutic potential of surplus exogenously applied IL-10 in APAP-induced ALI seems limited as administration of the recombinant cytokine failed to protect diseased mice (50).

Although this review focuses on cytokines efficiently targeting hepatocytes, it is important to note that modulation of murine APAP-induced ALI by endogenous IL-10 (and IL-13) unequivocally indicate a pivotal function of STAT3 also in myeloid cells (monocytes/macrophages/Kupffer cells) for determining course and outcome of APAP intoxication. Besides addressing STAT3 in hepatocytes, hepatic myeloid STAT3, thus, certainly is a further promising target for development of therapeutic strategies aiming at APAP-induced ALI.

\section{TRANSLATIONAL/THERAPEUTIC IMPLICATIONS AND CONCLUSIONS}

Administering hepatocyte STAT3-activating cytokines emerges from preclinical studies as encouraging pharmacological strategy that aims at hard-to-treat patients with APAP-induced ALI. Moreover, APAP intoxication may serve as paradigm for a whole group of injury-driven acute inflammatory liver diseases independent on the nature of the initiating insult (54). To translate preclinical knowledge to clinical application is, however, in some cases advantaged in others complicated by specific properties ascribed to aforementioned cytokines.

Although IL-6 displays significant tissue-protective characteristics, administration of the recombinant cytokine to patients is hampered by its pro-inflammatory effects especially on lymphocyte biology (61). Specifically, IL-6 promotes human IL-17 production and associated Th17 differentiation (98). Notably, IL-17 is pathogenic in murine APAP-induced ALI (19). As IL-6-induced Th17 associates with compromised Treg functions (99-101) and, 
if applicable, pathological antibody production (102), current knowledge supports serious concerns that administration of IL-6 to patients may initiate or enhance autoimmune inflammation.

Mice undergoing APAP toxicity did not benefit from exogenously provided IL-10 (50), which may likewise apply to human intoxication. As chief deactivator of leukocytes $(93,94)$, recombinant IL-10 should actually interfere with desired production of potentially pro-regenerative factors. In fact, this has been demonstrated for IL- 6 and TNF $\alpha$ production by human Kupffer cells under the influence of active TLR4 signaling (103).

Interleukin-11 and IL-22 are functionally related cytokines that efficiently activate hepatocyte STAT3 signaling and associated downstream gene expression. Both have been described to mediate tissue protection at host/environment interfaces, in particular at the digestive tract. For example, IL-11 $(104,105)$ and IL-22 $(106,107)$ display protective properties in Citrobacter rodentium-driven infectious as well as in trinitrobenzene sulfonic acid chemically induced experimental colitis. Accordingly, use of both cytokines is discussed, albeit with caution, for the treatment of inflammatory bowel diseases (108). Aforementioned liver protective properties of IL-11 and IL-22 are not restricted to APAP intoxication. Among others, experimental hepatic disorders mediated by reperfusion injury $(109,110)$ or administration of either carbon tetrachloride $(111,112)$ or concanavalin A $(112,113)$ likewise exposed beneficial effects of both cytokines. Although the role of IL-11 and IL-22 in liver repair/regeneration should primarily be mediated by STAT3, it must be stressed that activation of MAPK- and PI3K/Akt-pathways may support IL-11/IL-22 action in this context $(74,86,114)$. The feasibility of recombinant IL-11 therapy for the treatment of ALI is emphasized by its relatively favorable compatibility in clinical trials (115). In fact, recombinant IL-11 has been approved for the treatment of severe thrombocytopenia by the US Food and Drug Administration (79). At dosages showing biological activity, F-652 [Generon (Shanghai) Corporation Ltd.], an IL-22-like biopharmaceutical agent consisting of a human IL-22-Fc-fusion protein (116), is likewise reported to have a good safety profile as determined in a phase I study in healthy volunteers (http:// www.businesswire.com/news/home/20151123005647/en/ Generon-Collaborating-Mayo-Clinic-Initiate-Phase-IIa).

Pharmacotherapy of APAP-induced ALI must obviously be successful when initiated hours after ingestion. Whereas most studies assessed prophylactic treatment, therapeutic application has been investigated in a translational setting for IL-22. Specifically, when administered $2 \mathrm{~h}$ after APAP together with suboptimal $\mathrm{N}$-acetylcysteine dosing, recombinant IL-22

\section{REFERENCES}

1. Bernal W, Auzinger G, Dhawan A, Wendon J. Acute liver failure. Lancet (2010) 376(9736):190-201. doi:10.1016/S0140-6736(10)60274-7

2. Lee WM. Acetaminophen and the U.S. Acute Liver Failure Study Group: lowering the risks of hepatic failure. Hepatology (2004) 40(1):6-9. doi:10.1002/ hep. 20293

3. Brune K, Renner B, Tiegs G. Acetaminophen/paracetamol: a history of errors, failures and false decisions. Eur J Pain (2015) 19(7):953-65. doi:10.1002/ejp.621

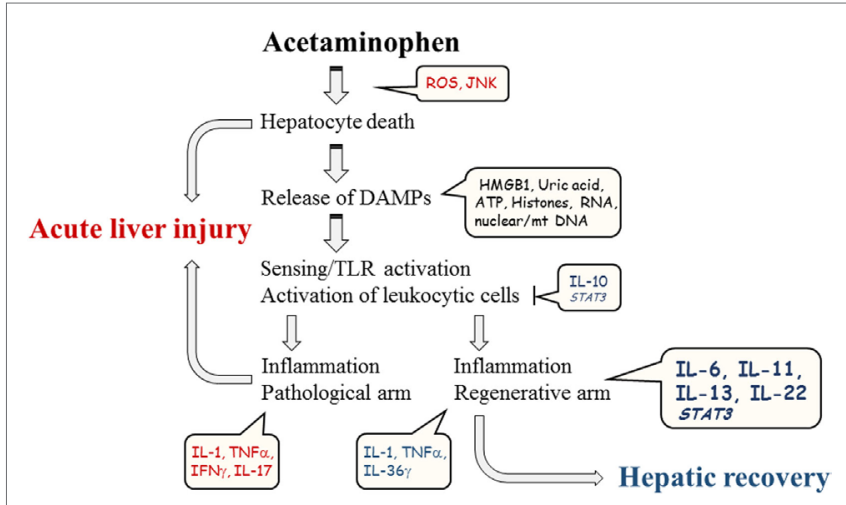

FIGURE 1 | Schematic illustration of major parameters contributing to course of experimental APAP-induced ALI.

improved murine intoxication (43). Notably, IL-22 application $2 \mathrm{~h}$ post-APAP is after the drop of cellular glutathione as well as the onset of APAP-adduct formation and liver necrosis $(43,117)$. More studies on treatment timing, however, are needed before experimental models can be translated to clinical intoxication.

Altogether, APAP-induced ALI is a complex disorder determined by the extent of initial hepatotoxicity, by the nature of adjacent sterile inflammation, and by the actual regenerative potential of the liver at the time of injury (Figure 1). Preclinical data suggest that providing recombinant STAT3-activating cytokines directly targeting hepatocytes, especially IL-11 and IL-22, may evolve as additional novel pro-regenerative therapeutic option in hard-to-treat patients where standard therapy with $\mathrm{N}$-acetylcysteine alone falls short. Notably, the benefit of focused short-term application of IL-11 or IL-22 in acute disorders, such as APAP-induced ALI, should likely outweigh the inherent danger of these cytokines to promote in the long run tumor growth $(74,86,118)$, which has been detected for IL-22 and hepatocellular carcinoma patients (118-120).

\section{AUTHOR CONTRIBUTIONS}

The author confirms being the sole contributor of this work and approved it for publication.

\section{FUNDING}

The work of the author is supported by a grant from the DFG (MU 1284/6-1).

4. Budnitz DS, Lovegrove MC, Crosby AE. Emergency department visits for overdoses of acetaminophen-containing products. Am J Prev Med (2011) 40(6):585-92. doi:10.1016/j.amepre.2011.02.026

5. Gulmez SE, Larrey D, Pageaux GP, Bernuau J, Bissoli F, Horsmans Y, et al. Liver transplant associated with paracetamol overdose: results from the seven-country SALT study. Br JClin Pharmacol (2015) 80(3):599-606. doi:10.1111/bcp.12635

6. Rotthauwe J. Wirksamkeit und Risiken von Paracetamol. Bulletin zur Arzneimittelsicherheit (2012) 3:11-3. 
7. Bantel $\mathrm{H}$, Schulze-Osthoff $\mathrm{K}$. Mechanisms of cell death in acute liver failure. Front Physiol (2012) 3:79. doi:10.3389/fphys.2012.00079

8. Jaeschke H, Xie Y, McGill MR. Acetaminophen-induced liver injury: from animal models to humans. J Clin Transl Hepatol (2014) 2(3):153-61. doi:10.14218/JCTH.2014.00014

9. Kubes P, Mehal WZ. Sterile inflammation in the liver. Gastroenterology (2012) 143(5):1158-72. doi:10.1053/j.gastro.2012.09.008

10. Maher JJ. DAMPs ramp up drug toxicity. J Clin Invest (2009) 119(2):246-9.

11. Brenner C, Galluzzi L, Kepp O, Kroemer G. Decoding cell death signals in liver inflammation. J Hepatol (2013) 59(3):583-94. doi:10.1016/j. jhep.2013.03.033

12. Jaeschke H, Williams CD, Ramachandran A, Bajt ML. Acetaminophen hepatotoxicity and repair: the role of sterile inflammation and innate immunity. Liver Int (2012) 32(1):8-20. doi:10.1111/j.1478-3231.2011.02501.x

13. Zaher H, Buters JT, Ward JM, Bruno MK, Lucas AM, Stern ST, et al. Protection against acetaminophen toxicity in CYP1A2 and CYP2E1 double-null mice. Toxicol Appl Pharmacol (1998) 152(1):193-9. doi:10.1006/taap.1998.8501

14. Hinson JA, Roberts DW, James LP. Mechanisms of acetaminophen-induced liver necrosis. Handb Exp Pharmacol (2010) 196:369-405. doi:10.1007/978-3-642-00663-0_12

15. Luedde T, Kaplowitz N, Schwabe RF. Cell death and cell death responses in liver disease: mechanisms and clinical relevance. Gastroenterology (2014) 147(4):765.e-83.e. doi:10.1053/j.gastro.2014.07.018

16. Matzinger P. The danger model: a renewed sense of self. Science (2002) 296(5566):301-5. doi:10.1126/science.1071059

17. Vénéreau E, Ceriotti C, Bianchi ME. DAMPs from cell death to new life. Front Immunol (2015) 6:422. doi:10.3389/fimmu.2015.00422

18. Huebener P, Pradere JP, Hernandez C, Gwak GY, Caviglia JM, Mu X, et al. The HMGB1/RAGE axis triggers neutrophil-mediated injury amplification following necrosis. J Clin Invest (2015) 125(2):539-50. doi:10.1172/JCI76887

19. Wang X, Sun R, Wei H, Tian Z. High-mobility group box 1 (HMGB1)-Tolllike receptor (TLR)4-interleukin (IL)-23-IL-17A axis in drug-induced damage-associated lethal hepatitis: interaction of $\gamma \delta \mathrm{T}$ cells with macrophages. Hepatology (2013) 57(1):373-84. doi:10.1002/hep.25982

20. Antoine DJ, Dear JW, Lewis PS, Platt V, Coyle J, Masson M, et al. Mechanistic biomarkers provide early and sensitive detection of acetaminophen-induced acute liver injury at first presentation to hospital. Hepatology (2013) 58(2):777-87. doi:10.1002/hep.26294

21. Xu J, Zhang X, Monestier M, Esmon NL, Esmon CT. Extracellular histones are mediators of death through TLR2 and TLR4 in mouse fatal liver injury. J Immunol (2011) 187(5):2626-31. doi:10.4049/jimmunol.1003930

22. Imaeda AB, Watanabe A, Sohail MA, Mahmood S, Mohamadnejad M, Sutterwala FS, et al. Acetaminophen-induced hepatotoxicity in mice is dependent on Tlr9 and the Nalp3 inflammasome. JClin Invest (2009) 119(2):305-14. doi:10.1172/JCI35958

23. Marques PE, Oliveira AG, Pereira RV, David BA, Gomides LF, Saraiva AM, et al. Hepatic DNA deposition drives drug-induced liver injury and inflammation in mice. Hepatology (2015) 61(1):348-60. doi:10.1002/hep.27216

24. Cavassani KA, Moreira AP, Habiel D, Ito T, Coelho AL, Allen RM, et al. Toll like receptor 3 plays a critical role in the progression and severity of acetaminophen-induced hepatotoxicity. PLoS One (2013) 8(6):e65899. doi:10.1371/ journal.pone.0065899

25. Hoque R, Farooq A, Malik A, Trawick BN, Berberich DW, McClurg JP, et al. A novel small-molecule enantiomeric analogue of traditional (-)-morphinans has specific TLR9 antagonist properties and reduces sterile inflammation-induced organ damage. J Immunol (2013) 190(8):4297-304. doi:10.4049/jimmunol.1202184

26. Hoque R, Sohail MA, Salhanick S, Malik AF, Ghani A, Robson SC, et al. P2X7 receptor-mediated purinergic signaling promotes liver injury in acetaminophen hepatotoxicity in mice. Am J Physiol Gastrointest Liver Physiol (2012) 302(10):G1171-9. doi:10.1152/ajpgi.00352.2011

27. Kono $\mathrm{H}$, Chen $\mathrm{CJ}$, Ontiveros F, Rock KL. Uric acid promotes an acute inflammatory response to sterile cell death in mice. JClin Invest (2010) 120(6):1939-49. doi:10.1172/JCI40124

28. Kataoka H, Yang K, Rock KL. The xanthine oxidase inhibitor Febuxostat reduces tissue uric acid content and inhibits injury-induced inflammation in the liver and lung. Eur J Pharmacol (2015) 746:174-9. doi:10.1016/j. ejphar.2014.11.013
29. Gombault A, Baron L, Couillin I. ATP release and purinergic signaling in NLRP3 inflammasome activation. Front Immunol (2013) 3:414. doi:10.3389/ fimmu.2012.00414

30. Martinon F. Mechanisms of uric acid crystal-mediated autoinflammation. Immunol Rev (2010) 233(1):218-32. doi:10.1111/j.0105-2896.2009.00860.x

31. Yohe HC, O'Hara KA, Hunt JA, Kitzmiller TJ, Wood SG, Bement JL, et al. Involvement of Toll-like receptor 4 in acetaminophen hepatotoxicity. Am J Physiol Gastrointest Liver Physiol (2006) 290(6):G1269-79. doi:10.1152/ ajpgi.00239.2005

32. Shah N, Montes de Oca M, Jover-Cobos M, Tanamoto K, Muroi M, Sugiyama K, et al. Role of toll-like receptor 4 in mediating multiorgan dysfunction in mice with acetaminophen induced acute liver failure. Liver Transpl (2013) 19(7):751-61. doi:10.1002/lt.23655

33. Cai C, Huang H, Whelan S, Liu L, Kautza B, Luciano J, et al. Benzyl alcohol attenuates acetaminophen-induced acute liver injury in a Toll-like receptor-4-dependent pattern in mice. Hepatology (2014) 60(3):990-1002. doi:10.1002/hep.27201

34. Kataoka H, Kono H, Patel Z, Kimura Y, Rock KL. Evaluation of the contribution of multiple DAMPs and DAMP receptors in cell death-induced sterile inflammatory responses. PLoS One (2014) 9(8):e104741. doi:10.1371/ journal.pone.0104741

35. Schnabl B, Brenner DA. Interactions between the intestinal microbiome and liver diseases. Gastroenterology (2014) 146(6):1513-24. doi:10.1053/j. gastro.2014.01.020

36. Böhm F, Köhler UA, Speicher T, Werner S. Regulation of liver regeneration by growth factors and cytokines. EMBO Mol Med (2010) 2(8):294-305. doi:10.1002/emmm.201000085

37. Fujiyoshi M, Ozaki M. Molecular mechanisms of liver regeneration and protection for treatment of liver dysfunction and diseases. J Hepatobiliary Pancreat Sci (2011) 18(1):13-22. doi:10.1007/s00534-010-0304-2

38. Miyaoka Y, Miyajima A. To divide or not to divide: revisiting liver regeneration. Cell Div (2013) 8(1):8. doi:10.1186/1747-1028-8-8

39. Bhushan B, Walesky C, Manley M, Gallagher T, Borude P, Edwards G, et al. Pro-regenerative signaling after acetaminophen-induced acute liver injury in mice identified using a novel incremental dose model. Am J Pathol (2014) 184(11):3013-25. doi:10.1016/j.ajpath.2014.07.019

40. Lesna M, Watson AJ, Douglas AP, Hamlyn AN, James OF. Evaluation of paracetamol-induced damage in liver biopsies. Acute changes and follow-up findings. Virchows Arch A Pathol Anat Histol (1976) 370(4):333-44. doi:10.1007/BF00445778

41. Dinarello CA. Proinflammatory and anti-inflammatory cytokines as mediators in the pathogenesis of septic shock. Chest (1997) 112(6 Suppl):321S-9S. doi:10.1378/chest.112.6_Supplement.321S

42. Williams CD, Farhood A, Jaeschke H. Role of caspase-1 and interleukin-1beta in acetaminophen-induced hepatic inflammation and liver injury. Toxicol Appl Pharmacol (2010) 247(3):169-78. doi:10.1016/j.taap.2010.07.004

43. Scheiermann P, Bachmann M, Goren I, Zwissler B, Pfeilschifter J, Mühl H. Application of interleukin-22 mediates protection in experimental acetaminophen-induced acute liver injury. Am J Pathol (2013) 182(4):1107-13. doi:10.1016/j.ajpath.2012.12.010

44. Dragomir AC, Sun R, Choi H, Laskin JD, Laskin DL. Role of galectin-3 in classical and alternative macrophage activation in the liver following acetaminophen intoxication. J Immunol (2012) 189(12):5934-41. doi:10.4049/ jimmunol.1201851

45. Henderson NC, Pollock KJ, Frew J, Mackinnon AC, Flavell RA, Davis RJ, et al. Critical role of c-jun (NH2) terminal kinase in paracetamol-induced acute liver failure. Gut (2007) 56(7):982-90. doi:10.1136/gut. 2006.104372

46. Liu ZX, Govindarajan S, Kaplowitz N. Innate immune system plays a critical role in determining the progression and severity of acetaminophen hepatotoxicity. Gastroenterology (2004) 127(6):1760-74. doi:10.1053/j. gastro.2004.08.053

47. Gandhi A, Guo T, Ghose R. Role of c-Jun N-terminal kinase (JNK) in regulating tumor necrosis factor-alpha (TNF-alpha) mediated increase of acetaminophen (APAP) and chlorpromazine (CPZ) toxicity in murine hepatocytes. J Toxicol Sci (2010) 35(2):163-73. doi:10.2131/jts.35.163

48. Blazka ME, Elwell MR, Holladay SD, Wilson RE, Luster MI. Histopathology of acetaminophen-induced liver changes: role of interleukin 1 alpha 
and tumor necrosis factor alpha. Toxicol Pathol (1996) 24(2):181-9. doi:10.1177/019262339602400206

49. Ishida Y, Kondo T, Tsuneyama K, Lu P, Takayasu T, Mukaida N. The pathogenic roles of tumor necrosis factor receptor p55 in acetaminophen-induced liver injury in mice. JLeukoc Biol (2004) 75(1):59-67. doi:10.1189/ jlb.0403152

50. Simpson KJ, Lukacs NW, McGregor AH, Harrison DJ, Strieter RM, Kunkel SL. Inhibition of tumour necrosis factor alpha does not prevent experimental paracetamol-induced hepatic necrosis. JPathol (2000) 190(4):489-94. doi:10.1002/(SICI)1096-9896(200003)190:4<489::AID -PATH534>3.3.CO;2-M

51. Yee SB, Bourdi M, Masson MJ, Pohl LR. Hepatoprotective role of endogenous interleukin-13 in a murine model of acetaminophen-induced liver disease. Chem Res Toxicol (2007) 20(5):734-44. doi:10.1021/tx600349f

52. Chiu H, Gardner CR, Dambach DM, Durham SK, Brittingham JA, Laskin JD, et al. Role of tumor necrosis factor receptor 1 (p55) in hepatocyte proliferation during acetaminophen-induced toxicity in mice. Toxicol Appl Pharmacol (2003) 193(2):218-27. doi:10.1016/j.taap.2003.07.003

53. James LP, Kurten RC, Lamps LW, McCullough S, Hinson JA. Tumour necrosis factor receptor 1 and hepatocyte regeneration in acetaminophen toxicity: a kinetic study of proliferating cell nuclear antigen and cytokine expression. Basic Clin Pharmacol Toxicol (2005) 97(1):8-14. doi:10.111 1/j.1742-7843.2005.pto_97102.x

54. Wang H, Lafdil F, Kong X, Gao B. Signal transducer and activator of transcription 3 in liver diseases: a novel therapeutic target. Int J Biol Sci (2011) 7(5):536-50. doi:10.7150/ijbs.7.536

55. Chen CJ, Kono H, Golenbock D, Reed G, Akira S, Rock KL. Identification of a key pathway required for the sterile inflammatory response triggered by dying cells. Nat Med (2007) 13(7):851-6. doi:10.1038/nm1603

56. Ishibe $\mathrm{T}$, Kimura $\mathrm{A}$, Ishida $\mathrm{Y}$, Takayasu $\mathrm{T}$, Hayashi $\mathrm{T}$, Tsuneyama $\mathrm{K}$, et al. Reduced acetaminophen-induced liver injury in mice by genetic disruption of IL-1 receptor antagonist. Lab Invest (2009) 89(1):68-79. doi:10.1038/ labinvest.2008.110

57. Gabay C, Towne JE. Regulation and function of interleukin-36 cytokines in homeostasis and pathological conditions. J Leukoc Biol (2015) 97(4):645-52. doi:10.1189/jlb.3RI1014-495R

58. Scheiermann P, Bachmann M, Härdle L, Pleli T, Piiper A, Zwissler B, et al. Application of IL-36 receptor antagonist weakens CCL20 expression and impairs recovery in the late phase of murine acetaminophen-induced liver injury. Sci Rep (2015) 5:8521. doi:10.1038/srep08521

59. Medina-Contreras O, Harusato A, Nishio H, Flannigan KL, Ngo V, Leoni G, et al. Cutting edge: IL-36 receptor promotes resolution of intestinal damage. J Immunol (2016) 196(1):34-8. doi:10.4049/jimmunol.1501312

60. Scheibe K, Backert I, Wirtz S, Hueber A, Schett G, Vieth M, et al. IL-36R signalling activates intestinal epithelial cells and fibroblasts and promotes mucosal healing in vivo. Gut (2016). doi:10.1136/gutjnl-2015-310374

61. Tanaka T, Narazaki M, Kishimoto T. IL-6 in inflammation, immunity, and disease. Cold Spring Harb Perspect Biol (2014) 6(10):a016295. doi:10.1101/ cshperspect.a016295

62. Yu H, Jove R. The STATs of cancer - new molecular targets come of age. Nat Rev Cancer (2004) 4(2):97-105. doi:10.1038/nrc1275

63. Jarnicki A, Putoczki T, Ernst M. Stat3: linking inflammation to epithelial cancer - more than a "gut" feeling? Cell Div (2010) 5:14. doi:10.1186/1747-1028-5-14

64. Qi QR, Yang ZM. Regulation and function of signal transducer and activator of transcription 3. World J Biol Chem (2014) 5(2):231-9. doi:10.4331/wjbc. v5.i2.231

65. Rébé C, Végran F, Berger H, Ghiringhelli F. STAT3 activation: a key factor in tumor immunoescape. JAKSTAT (2013) 2(1):e23010. doi:10.4161/jkst.23010

66. Zhuang S. Regulation of STAT signaling by acetylation. Cell Signal (2013) 25(9):1924-31. doi:10.1016/j.cellsig.2013.05.007

67. Kim J, Won JS, Singh AK, Sharma AK, Singh I. STAT3 regulation by S-nitrosylation: implication for inflammatory disease. Antioxid Redox Signal (2014) 20(16):2514-27. doi:10.1089/ars.2013.5223

68. Droescher M, Begitt A, Marg A, Zacharias M, Vinkemeier U. Cytokineinduced paracrystals prolong the activity of signal transducers and activators of transcription (STAT) and provide a model for the regulation of protein solubility by small ubiquitin-like modifier (SUMO). J Biol Chem (2011) 286(21):18731-46. doi:10.1074/jbc.M111.235978
69. Li W, Liang X, Kellendonk C, Poli V, Taub R. STAT3 contributes to the mitogenic response of hepatocytes during liver regeneration. J Biol Chem (2002) 277(32):28411-7. doi:10.1074/jbc.M202807200

70. Feng D, Wang Y, Wang H, Weng H, Kong X, Martin-Murphy BV, et al. Acute and chronic effects of IL-22 on acetaminophen-induced liver injury. J Immunol (2014) 193(5):2512-8. doi:10.4049/jimmunol.1400588

71. Nishina T, Komazawa-Sakon S, Yanaka S, Piao X, Zheng DM, Piao JH, et al. Interleukin-11 links oxidative stress and compensatory proliferation. Sci Signal (2012) 5(207):ra5. doi:10.1126/scisignal.2002056

72. Ishida Y, Kondo T, Ohshima T, Fujiwara H, Iwakura Y, Mukaida N. A pivotal involvement of IFN-gamma in the pathogenesis of acetaminophen-induced acute liver injury. FASEB J (2002) 16(10):1227-36. doi:10.1096/f.02-0046com

73. Masubuchi Y, Bourdi M, Reilly TP, Graf ML, George JW, Pohl LR. Role of interleukin-6 in hepatic heat shock protein expression and protection against acetaminophen-induced liver disease. Biochem Biophys Res Commun (2003) 304(1):207-12. doi:10.1016/S0006-291X(03)00572-2

74. Ernst M, Putoczki TL. Molecular pathways: IL11 as a tumor-promoting cytokine-translational implications for cancers. Clin Cancer Res (2014) 20(22):5579-88. doi:10.1158/1078-0432.CCR-13-2492

75. James LP, Lamps LW, McCullough S, Hinson JA. Interleukin 6 and hepatocyte regeneration in acetaminophen toxicity in the mouse. Biochem Biophys Res Commun (2003) 309(4):857-63. doi:10.1016/j.bbrc.2003.08.085

76. Hogaboam CM, Bone-Larson CL, Steinhauser ML, Lukacs NW, Colletti LM, Simpson KJ, et al. Novel CXCR2-dependent liver regenerative qualities of ELR-containing CXC chemokines. FASEB J (1999) 13(12):1565-74.

77. Drucker C, Gewiese J, Malchow S, Scheller J, Rose-John S. Impact of interleukin-6 classic- and trans-signaling on liver damage and regeneration. J Autoimmun (2010) 34(1):29-37. doi:10.1016/j.jaut.2009.08.003

78. Li SQ, Zhu S, Han HM, Lu HJ, Meng HY. IL-6 trans-signaling plays important protective roles in acute liver injury induced by acetaminophen in mice. J Biochem Mol Toxicol (2015) 29(6):288-97. doi:10.1002/jbt.21708

79. Garbers C, Scheller J. Interleukin-6 and interleukin-11: same same but different. Biol Chem (2013) 394(9):1145-61. doi:10.1515/hsz-2013-0166

80. Trepicchio WL, Bozza M, Bouchard P, Dorner AJ. Protective effect of rhIL-11 in a murine model of acetaminophen-induced hepatotoxicity. Toxicol Pathol (2001) 29(2):242-9. doi:10.1080/019262301317052521

81. Du K, Williams CD, McGill MR, Jaeschke H. Lower susceptibility of female mice to acetaminophen hepatotoxicity: role of mitochondrial glutathione, oxidant stress and c-jun N-terminal kinase. Toxicol Appl Pharmacol (2014) 281(1):58-66. doi:10.1016/j.taap.2014.09.002

82. May RD, Fung M. Strategies targeting the IL-4/IL-13 axes in disease. Cytokine (2015) 75(1):89-116. doi:10.1016/j.cyto.2015.05.018

83. Stanya KJ, Jacobi D, Liu S, Bhargava P, Dai L, Gangl MR, et al. Direct control of hepatic glucose production by interleukin-13 in mice. J Clin Invest (2013) 123(1):261-71. doi:10.1172/JCI64941

84. Bourdi M, Masubuchi Y, Reilly TP, Amouzadeh HR, Martin JL, George JW, et al. Protection against acetaminophen-induced liver injury and lethality by interleukin 10: role of inducible nitric oxide synthase. Hepatology (2002) 35(2):289-98. doi:10.1053/jhep.2002.30956

85. Doherty TM, Kastelein R, Menon S, Andrade S, Coffman RL. Modulation of murine macrophage function by IL-13. J Immunol (1993) 151(12):7151-60.

86. Mühl H, Scheiermann P, Bachmann M, Härdle L, Heinrichs A, Pfeilschifter J. IL-22 in tissue-protective therapy. Br J Pharmacol (2013) 169(4):761-71. doi:10.1111/bph.12196

87. Sabat R, Ouyang W, Wolk K. Therapeutic opportunities of the IL-22-IL-22R1 system. Nat Rev Drug Discov (2014) 13(1):21-38. doi:10.1038/nrd4176

88. Dudakov JA, Hanash AM, van den Brink MR. Interleukin-22: immunobiology and pathology. Annu Rev Immunol (2015) 33:747-85. doi:10.1146/ annurev-immunol-032414-112123

89. Bachmann M, Ulziibat S, Härdle L, Pfeilschifter J, Mühl H. IFN $\alpha$ converts IL-22 into a cytokine efficiently activating STAT1 and its downstream targets. Biochem Pharmacol (2013) 85(3):396-403. doi:10.1016/j. bcp.2012.11.004

90. Mühl H. Pro-inflammatory signaling by IL-10 and IL-22: bad habit stirred up by interferons? Front Immunol (2013) 4:18. doi:10.3389/fimmu.2013.00018

91. Hernández PP, Mahlakõiv T, Yang I, Schwierzeck V, Nguyen N, Guendel F, et al. Interferon- $\lambda$ and interleukin 22 act synergistically for the induction of interferon-stimulated genes and control of rotavirus infection. Nat Immunol (2015) 16(7):698-707. doi:10.1038/ni.3180 
92. Lamarthée B, Malard F, Gamonet C, Bossard C, Couturier M, Renauld JC, et al. Donor interleukin-22 and host type I interferon signaling pathway participate in intestinal graft-versus-host disease via STAT1 activation and CXCL10. Mucosal Immunol (2016) 9(2):309-21. doi:10.1038/ mi.2015.61

93. Ouyang W, Rutz S, Crellin NK, Valdez PA, Hymowitz SG. Regulation and functions of the IL-10 family of cytokines in inflammation and disease. Annu Rev Immunol (2011) 29:71-109. doi:10.1146/annurev-immunol-031210-101312

94. Mocellin S, Marincola F, Rossi CR, Nitti D, Lise M. The multifaceted relationship between IL-10 and adaptive immunity: putting together the pieces of a puzzle. Cytokine Growth Factor Rev (2004) 15(1):61-76. doi:10.1016/j. cytogfr.2003.11.001

95. Mühl H, Bachmann M, Pfeilschifter J. Inducible NO synthase and antibacterial host defence in times of Th17/Th22/T22 immunity. Cell Microbiol (2011) 13(3):340-8. doi:10.1111/j.1462-5822.2010.01559.x

96. Stumhofer JS, Silver JS, Laurence A, Porrett PM, Harris TH, Turka LA, et al. Interleukins 27 and 6 induce STAT3-mediated T cell production of interleukin 10. Nat Immunol (2007) 8(12):1363-71. doi:10.1038/ni1537

97. Kinjyo I, Inoue H, Hamano S, Fukuyama S, Yoshimura T, Koga K, et al. Loss of SOCS3 in T helper cells resulted in reduced immune responses and hyperproduction of interleukin 10 and transforming growth factor-beta 1 . J Exp Med (2006) 203(4):1021-31. doi:10.1084/jem.20052333

98. Acosta-Rodriguez EV, Napolitani G, Lanzavecchia A, Sallusto F. Interleukins lbeta and 6 but not transforming growth factor-beta are essential for the differentiation of interleukin 17-producing human T helper cells. Nat Immunol (2007) 8(9):942-9. doi:10.1038/ni1496

99. Goodman WA, Levine AD, Massari JV, Sugiyama H, McCormick TS, Cooper KD. IL-6 signaling in psoriasis prevents immune suppression by regulatory $\mathrm{T}$ cells. JImmunol (2009) 183(5):3170-6. doi:10.4049/ jimmunol.0803721

100. Samson M, Audia S, Janikashvili N, Ciudad M, Trad M, Fraszczak J, et al. Brief report: inhibition of interleukin- 6 function corrects Th17/Treg cell imbalance in patients with rheumatoid arthritis. Arthritis Rheum (2012) 64(8):2499-503. doi:10.1002/art.34477

101. Kimura A, Kishimoto T. IL-6: regulator of Treg/Th17 balance. Eur J Immunol (2010) 40(7):1830-5. doi:10.1002/eji.201040391

102. Nishimoto N, Kishimoto T. Interleukin 6: from bench to bedside. Nat Clin Pract Rheumatol (2006) 2(11):619-26. doi:10.1038/ncprheum0372

103. Knolle P, Schlaak J, Uhrig A, KempfP, Meyer zum Büschenfelde KH, Gerken G. Human Kupffer cells secrete IL-10 in response to lipopolysaccharide (LPS) challenge. J Hepatol (1995) 22(2):226-9. doi:10.1016/0168-8278(95)80433-1

104. Gibson DL, Montero M, Ropeleski MJ, Bergstrom KS, Ma C, Ghosh S, et al. Interleukin-11 reduces TLR4-induced colitis in TLR2-deficient mice and restores intestinal STAT3 signaling. Gastroenterology (2010) 139(4):1277-88. doi:10.1053/j.gastro.2010.06.057

105. Qiu BS, Pfeiffer CJ, Keith JC Jr. Protection by recombinant human interleukin-11 against experimental TNB-induced colitis in rats. Dig Dis Sci (1996) 41(8):1625-30. doi:10.1007/BF02087911

106. Zheng Y, Valdez PA, Danilenko DM, Hu Y, Sa SM, Gong Q, et al. Interleukin-22 mediates early host defense against attaching and effacing bacterial pathogens. Nat Med (2008) 14(3):282-9. doi:10.1038/nm1720

107. Monteleone I, Rizzo A, Sarra M, Sica G, Sileri P, Biancone L, et al. Aryl hydrocarbon receptor-induced signals up-regulate IL-22 production and inhibit inflammation in the gastrointestinal tract. Gastroenterology (2011) 141(1):237-48.e1. doi:10.1053/j.gastro.2011.04.007
108. Nguyen PM, Putoczki TL, Ernst M. STAT3-activating cytokines: a therapeutic opportunity for inflammatory bowel disease? Interferon Cytokine Res (2015) 35(5):340-50. doi:10.1089/jir.2014.0225

109. Zhu M, Lu B, Cao Q, Wu Z, Xu Z, Li W, et al. IL-11 attenuates liver ischemia/ reperfusion injury (IRI) through STAT3 Signaling Pathway in Mice. PLoS One (2015) 10(5):e0126296. doi:10.1371/journal.pone.0126296

110. Chestovich PJ, Uchida Y, Chang W, Ajalat M, Lassman C, Sabat R, et al. Interleukin-22: implications for liver ischemia-reperfusion injury. Transplantation (2012) 93(5):485-92. doi:10.1097/TP.0b013e3182449136

111. Kuhara T, Tanaka A, Yamauchi K, Iwatsuki K. Bovine lactoferrin ingestion protects against inflammation via IL-11 induction in the small intestine of mice with hepatitis. Br JNutr (2014) 111(10):1801-10. doi:10.1017/ S0007114513004315

112. Radaeva S, Sun R, Pan HN, Hong F, Gao B. Interleukin 22 (IL-22) plays a protective role in T cell-mediated murine hepatitis: IL-22 is a survival factor for hepatocytes via STAT3 activation. Hepatology (2004) 39(5):1332-42. doi:10.1002/hep.20184

113. Bozza M, Bliss JL, Maylor R, Erickson J, Donnelly L, Bouchard P, et al. Interleukin-11 reduces T-cell-dependent experimental liver injury in mice. Hepatology (1999) 30(6):1441-7. doi:10.1002/hep.510300616

114. Brand S, Dambacher J, Beigel F, Zitzmann K, Heeg MH, Weiss TS, et al. IL-22-mediated liver cell regeneration is abrogated by SOCS-1/3 overexpression in vitro. Am J Physiol Gastrointest Liver Physiol (2007) 292(4):G1019-28. doi:10.1152/ajpgi.00239.2006

115. Gordon MS, McCaskill-Stevens WJ, Battiato LA, Loewy J, Loesch D, Breeden E, et al. A phase I trial of recombinant human interleukin-11 (neumega rhIL-11 growth factor) in women with breast cancer receiving chemotherapy. Blood (1996) 87(9):3615-24.

116. Lindemans CA, Calafiore M, Mertelsmann AM, O'Connor MH, Dudakov JA Jenq RR, et al. Interleukin-22 promotes intestinal-stem-cell-mediated epithelial regeneration. Nature (2015) 528(7583):560-4. doi:10.1038/nature16460

117. Roberts DW, Bucci TJ, Benson RW, Warbritton AR, McRae TA, Pumford NR, et al. Immunohistochemical localization and quantification of the 3-(cystein-S-yl)-acetaminophen protein adduct in acetaminophen hepatotoxicity. Am J Pathol (1991) 138(2):359-71.

118. Lim C, Savan R. The role of the IL-22/IL-22R1 axis in cancer. Cytokine Growth Factor Rev (2014) 25(3):257-71. doi:10.1016/j.cytogfr.2014.04.005

119. Jiang R, Tan Z, Deng L, Chen Y, Xia Y, Gao Y, et al. Interleukin-22 promotes human hepatocellular carcinoma by activation of STAT3. Hepatology (2011) 54(3):900-9. doi:10.1002/hep.24486

120. Waidmann O, Kronenberger B, Scheiermann P, Köberle V, Mühl H, Piiper A. Interleukin-22 serum levels are a negative prognostic indicator in patients with hepatocellular carcinoma. Hepatology (2014) 59(3):1207. doi:10.1002/ hep. 26528

Conflict of Interest Statement: The author declares that the research was conducted in the absence of any commercial or financial relationships that could be construed as a potential conflict of interest.

Copyright (C) 2016 Mühl. This is an open-access article distributed under the terms of the Creative Commons Attribution License (CC BY). The use, distribution or reproduction in other forums is permitted, provided the original author(s) or licensor are credited and that the original publication in this journal is cited, in accordance with accepted academic practice. No use, distribution or reproduction is permitted which does not comply with these terms. 